\title{
FOVEAL ELECTRORETINOGRAM AS A CLINICAL TEST*
}

\author{
BY \\ G. B. ARDEN AND J. L. K. BANKES \\ Department of Neurophysiology, Institute of Ophthalmology, University of London
}

THE electroretinogram (ERG) is used as an objective test of retinal function. However, in normal clinical recording, the potential investigated is produced by the entire retina (Asher, 1951). Therefore, though diffuse retinal damage can be detected, normal responses are obtained if the lesion is small and localized, such as a macular degeneration.

It has been shown in animal experiments that local ERGs can be obtained by using micro-electrodes (Brown and Wiesel, 1959). More recently local responses have been obtained in experimental subjects using corneal electrodes and averaging techniques (Brindley and Westheimer, 1965). It is the purpose of this communication to show that such techniques can be used to obtain true foveal ERGs and are practicable in clinical circumstances.

Patients and normal subjects were fitted with standard contact lens electrodes (modified Karpe type) and no correction for refractive error was incorporated. The stimulus was a back-illuminated diffuser $1.5 \mathrm{~cm}$. in diameter at $43 \mathrm{~cm}$., subtending a visual angle of $2^{\circ}$. Its retinal image covered either the fovea or the blind spot. The front face of the diffuser was surrounded by a large piece of white card, illuminated by a blue-green light. The stimulus flashes $(150 / \mathrm{min}$.) were provided by a Xenon stroboscope, covered by a red filter. Broadband filters made of sheets of "Cinemoid" were used.

When the stimulus fell on the blind spot and there was no blue-green background, a "diffuse" ERG could be obtained. The background intensity was increased till this vanished (less than $0.5 \mu \mathrm{V}$ of potential averaged from 150 responses, using a Mnemotron CAT). If the stimulus was now shifted to the fovea, well marked $a$ and $b$ waves of peak amplitude approx. $10 \mu \mathrm{V}$ were recorded, using the same averaging technique. The responses were much smaller if the stimulus colour was green or blue, or if the stimuli fell on the retinal periphery. Thus the ERG was obtained from the photopic mechanism, and was generated by the neurones and receptors directly under the physical image of the stimulus.

Patients have been tested using these stimulus parameters. In one case of unilateral macular degeneration, an extinguished foveal ERG was obtained from the affected side, and a normal response from the other eye. In other patients with bilateral involvement, abnormal ERGs of reduced amplitude were recorded. In all these patients, the disease was strictly limited to the fovea.

It seems, therefore, that with standard contact lenses the foveal responses of unselected patients can be investigated in this way.

Asher, H. (1951). J. Physiol. (Lond.), 112, 40 P.

Brindley, G. S., and Westheimer, G. (1965). Ibid., 179, 518.

Brown, K. T., and Wiesel, T. N. (1959). Ibid., 149, 537.

* Received for publication September 2, 1966.

† Address for reprints: Institute of Ophthalmology, Judd St., London, W.C.1. 